\title{
Recent Researches on the Causation of Tumours.
}

\section{By Prof. William Bulloch, F.R.S.}

A WEEK or two ago it was rumoured that remarkable additions had been made to our knowledge of tumours by Dr W. E. Gye, of the scientific staff of the Medical Research Council. Instantly, almost every newspaper took the report up, some of them announcing with sensational headlines that the problem of cancer was solved and that the disease was due to a small germ. Dr. Gye's collaborator, Mr. J. E. Barnard, F.R.S.-a well-known scientist-was said to have secured photographs of the virus, and it was alleged that it had actually been cultivated. What the real facts were, was only the property of a few, because the papers of Gye and Barnard were not published until some days later. In the absence of details, a short note appeared in NATURE of July I8-the day of publication of Gye's paper-giving a general statement of the results said to be claimed, and so far as they were known. It is now possible to write more fully and with greater confidence as a result of the study of the papers just published (Lancet, July I8).

Unlike many fantastic hypotheses which have been proposed to explain the cause of tumours, the present one comes from a scientific worker who has the very highest credentials and is known not only in England but also all over the scientific medical world. Behind him is a wide experience, particularly of the kind of work on which he now reports, and he is known for his imaginative and critical powers, his sober judgment, and his high technical skill.

William Ewart Gye is a man about forty years of age who graduated M.D. Edinburgb in 1913 and came to London to be assistant in the laboratories of the Imperial Cancer Research Fund about a dozen years ago. His appearances in scientific gatherings stamped him at once as a quite unusual man, modest but efficient, full of scientific enthusiasm, but temperate and cautious in the estimate of his own work and that of others. During the War he carried out very important investigations which cleared up several of the mysteries in the pathology of gas gangrene and lockjaw and secured him a post on the staff of the Medical Research Council. When the Council inaugurated a scheme for the study of the unknown viruses of certain infective diseases, like distemper, Gye took his part, but early struck out on his own lines and, working by himself, has completed the research just published. This work is of the greatest interest and, if confirmed, will be found to open up entirely new fields not only in what has hitherto been a veritable slough of despondcancer-but also in connexion with many other diseases, of unknown causation, affecting man and animals. Gye's paper in the Lancet is entitled "The Atiology of Malignant New Growths" and is prefaced by a short paragraph quoted from a leader on the subject in the same issue. It is unusual and often unwise to attempt to forecast what the ultimate value of a scientific paper will be, but the Lancet is of opinion that the two papers of Gye and Barnard "mark an event in the history of medicine." This may or may not be so, and we may note that the leader writer, in the next sentence, is more moderate when he states that they may present a solution of the central problem of cancer.
The critical study of Gye's paper leads one to the conclusion that, if his results are confirmed by independent workers, he has made a discovery of the greatest interest and possibly of the highest importance to the well-being of man. Before dealing with his data as presented, and as the subject is one which will be followed by scientific as well as non-scientific readers, it would appear well to clear the ground and state what was commonly accepted on the subject of malignant disease before Gye's publication, and it may be affirmed at once that but little of this knowledge has been controverted by his work.

It is known that all races of man and animals are liable to the development of tumours or swellingsnow called blastomata-which possess certain common and constant features. No tumour has yet been seen that was not composed of some tissue of the body of the individual in which it arose. For some unknown reason a tissue begins to grow in excess, and this growth, barring operation or accident, is unlimited in extent. There is an infinite variety in the structure of tumours arising from different or even from one and the same tissue, and quite early an important line of demarcation was drawn on practical grounds between tumours that were clinically or histologically benign and those which were malignant and destructive of life. The differentiation is, however, not always easy, or indeed always possible. From remote times, two special malignant tumours have attracted interest on account of their deadly character. These tumourssarcoma and cancer-start in a particular tissue but early burst into other tissues. Invading blood-vessels and lymph vessels, and being swept away in the circulating blood, the cells are carried throughout the body, halting in numerous backwaters to produce secondary tumours or metastases. There is an irrefutable body of evidence, confirmed daily, that the secondary tumours are composed of cells which are the descendants of the cells of the primary tumour.

The central problem of tumour formation is to nnd out what has caused this aimless growth of cells previously-so far as one can judge-perfectly normal. It is this problem which Gye has attempted and is reputed to have solved. There have, naturally, been many hypotheses on the subject of the cause of tumours, but two have gradually been accepted as the most probable. In one, evidence has been sought experimentally and otherwise that the purposeless growth of the cells is due to some kind of chemical irritant acting on normal, or possibly abnormal, cells. The other view, early held and long studied, attributed the cause of tumours, particularly malignant growths, to the action of some extrinsic parasite which, entering the body, stimulated the cells to unwonted activities. Many parasites of microscopic size have been incriminated at various times during the last forty years, but none has fulfilled the test of tumour production experimentally, and however much the study of malignant disease suggests an infection, the vast majority of those with special knowledge were compelled to reject a parasitic hypothesis on various grounds. No parasite, not even that said to exist by

No. 2908, vol. II6] 
Gye, has by its inoculation caused by itself the development of a malignant or other blastomatous growth. Further, there is a marvellous specificity in all growths whereby they copy, in every degree of variation, the tissue from which they arose. Those facts forced investigators to the conclusion that, when one remembers the extraordinarily wide zoological range in which tumours occur, the cause is some deep-seated mystery connected with the processes of birth, growth, and decay of the cells of the body.

In 1902, C. O. Jensen, of Copenhagen, discovered by accident a malignant tumour in a mouse, and worked it out so carefully that his paper has become a classic in the literature. He failed to find any evidence of a parasite either in the original growth or in those transmitted by transplantation to other mice. He showed that no growths followed the inoculation of tumour cells that had been crushed. Since Jensen's time, many similar tumours have been studied and transmitted in an unbroken series of generations, and Jensen's statements have been confirmed over and over again. Even before Jensen, several workers, among whom we may specially mention BellinghamSmith and Washbourn in England, had shown that certain tumour-like formations were transmissible from $\operatorname{dog}$ to dog, but the exact nature of the growths was the subject of mush dispute.

In I9ro, a new, and, as it proves, highly important, work was published by Peyton Rous, of the Rockefeller Institute, N.Y. He found a tumour growing in the breast of a barred Plymouth Rock hen. The tumour proved to be transmissible to other hens of the same setting, and in structure was regarded as a genuine sarcoma. Transmission, at first, was not easy, but in the course of passage from one fowl to another the growth became more malignant in its effects and lethal within a few weeks. In rgIr, Rous made the further, highly important, discovery that when portions of the sarcoma were ground up and passed through filter paper, or even through a Berkefeld Kieselguhr filter, the cell-free filtrate contained some "agent" which could communicate the sarcoma disease to normal fowls. No microbe could be seen in, or be grown from, the clear filtrate, and Rous left it an open question whether it was to be regarded as containing a living microbe. "It is conceivable," he said, " that a chemical stimulant elaborated by the neoplastic cells might cause the tumour in another host and bring about in consequence a further production of the same stimulant."

The fact that the cell-free filtrates were capable of producing tumours was something quite new, but was soon found not to be unique, for between I9II and I9r 3 Rous, in conjunction with Murphy, Tytler, or Lange, found two other fowl tumours transmissible in this way. He also showed in the case of the first tumour ("Rous sarcoma I.") that ultra-violet light rapidly destroys the activity of the sarcoma cells without destroying the filterable agent associated with them. From irradiation experiments he made out that in the sarcomatous tissue there are apparently two elements capable of producing the growth. One will withstand drying, the other will not. The latter is the living transplantable cells, whereas the former is the tumour-producing agent.
Coming to Gye's work, full credit is given to Rous for his admirable researches on the Rous sarcoma I. It is with this tumour that Gye has mostly made his experiments. His main thesis is that the "agent" is really a living virus. This virus is incapable by itself of producing a tumour. For the latter, there has to be the co-operation of a second factor-the "specific factor "-also incapable by itself of inducing a sarcoma, but which enables the living virus to attack the cells of the inoculated animal and transform them into malignant cells. The impression gained from a careful perusal of Gye's paper is that he has more facts than he has yet divulged. The experiments he has given us are carefully thought out and precisely described. A medium-probably not the best one--is indicated in which he obtains " primary cultures"-_ " a term of convenience," he says, applied to the result of placing a fragment of tumour in the medium. He found that in a tube of " primary culture " the supernatant liquor becomes infective, depending on various factors of which anaerobiosis is said to be the most important. That the " primary culture" contains something living is suggested by the definite acid reaction which ensues when glucose, maltose, or lævulose are incorporated in the medium. No such reactions occur in the presence of mannitol, lactose, or sucrose. It is believed that the "agent" of the tumour diffuses out in the medium and that it disappears slowly (days).

Of fundamental importance for the support of Gye's views are his experiments on the action of chloroform on the tumour agent. It had been previously shown by Rous that carbolic acid, toluol or chloroform destroys the power of the "agent" to induce tumours. In a series of experiments, repeated, it is stated, with constant results, Gye shows that a "primary culture" incubated aerobically for three days at $37^{\circ} \mathrm{C}$. produced no tumour when injected into fowls. The clear tumour filtrate thoroughly treated with chloroform was also incapable of inducing growth. But the two inert fractions mixed together were found to produce typical sarcomata. The interpretation given by Gye is that the chloroform-treated filtrate contains a labile chemical substance which in some way, unknown, renders the cells susceptible to the supposed virus, presumed to be present in the other fraction, which was incubated at $37^{\circ} \mathrm{C}$. for three days. Gye's conception of a double factor was also supported by centrifugation experiments, for although it was not found possible to drive the virus to the bottom of the tubes spun at high rates, some concentration in special lined tubes did appear to occur. Of the two factors necessary for the production of a Rous sarcoma, Gye believes that one is particulate and is therefore "probably a virus," the other, uninfluenced by centrifugation, being a chemical substance. Since the supposed virus is incapable of producing a tumour, and since the tumours when they originate are specific, Gye admits that the "specific factor" must be the important thing when the action of the two is considered.

Attempts were made to demonstrate that the "virus" actually multiplies in cultures. In one experiment, a fifth subculture in direct line from a "primary culture" produced no tumour, nor did a chloroformed filtrate, but when the two were mixed, 
tumours were produced and were lethal in twenty-three days. As each subculture represented a dilution of rooo fold, the dilution of the matter in the "primary culture "would be $10^{\mathbf{1 5}}$ if it had not increased.

These remarkable results with the Rous sarcoma I. were followed up on other tumours of known origin and history. They included a spindle cell sarcoma " $37 / \mathrm{S}$," the Jensen rat sarcoma, carcinoma of mouse "No. 63," and a rat sarcoma known as "No. 9." Directly or indirectly, experiments with these tumours confirmed the results with the Rous sarcoma I. In each case the "specific factor" was the important one, the virus being less so. Thus a chloroform extract from Rous sarcoma was found to be incapable of producing the disease. A " primary culture" from mouse cancer "63" was also inert when tested on fowls. The specific factor of the fowl plus the "culture "from the mouse produced sarcoma in the fowl. This astonishing result was also obtained in the case of an adenocarcinoma of the human breast. Inert "specific factor" from fowl tumour, plus inert " primary culture " from human tumour, caused sarcoma in the fowl.

That briefly and perhaps imperfectly represents the main results of Gye's published work. Of the proof of the "virus" he speaks guardedly. It is said to be "almost certainly a virus." The idea of two factors in the production of a disease is not a new one. It has, indeed, long been a commonplace of medical writers that the development of most diseases requires the co-operation of two sets of factors. On one hand, the organism within which the morbid process is to unfold itself must conform to certain conditions of structure and function. This is the so-called "internal" cause. On the other hand, some agent, the " external" cause, actually or functionally outside the organism, must exert an effect peculiar to itself, and a property of its own structure, upon the organism which is in process of becoming the seat of the disease. The revolutions in medical knowledge which came from bacteriological discoveries showed that for most infective diseases the specific agent was the external one. Thus the tubercle bacillus is the specific element in tuberculosis. In the case of tumours-if Gye's work is confirmed-it would appear that the specificity is not resident in the virus but in the "internal" cause-a new conception in connexion with infective disease. Gye's work may be the central point round which the cancer problem revolves. It is certainly a long way from the complete solution of tumour formation, although one must be frank and congratulate Dr. Gye on opening up a new field pregnant with possibilities.

With reference to Mr. Barnard's paper, this deals largely with the question of the microscopic examination of "ultra visible" agents. The agent chiefly described is the microbe of bovine pleuro-pneumonia, in which various morphological types are reproduced. Very little is said of the "virus" of Rous sarcoma and other tumours except that the same morphological types can be seen as occur in bovine pleuro-pneumonia. Attention is directed to the care necessary in excluding various "bodies" which are seen in uninoculated tubes. Finally, there is a combined note by Gye and Barnard. Their exact words may be here reproduced. "Our belief that the small bodies seen and photographed are the actual virus depends partly upon the fact that control uninoculated tubes of medium have been invariably blank and partly upon the correspondence between the microscopical findings and the results of experiments on animals. This correspondence-allowing for the real difficulties in both parts of the common task-has been so close that although final proof has not been attained we are convinced that our conclusions are sound."

\section{Current Topics and Events.}

PrIor to the War, there was in force an Order of the Board of Agriculture compelling the slaughter of cattle discovered to be suffering from tuberculosis of the udder and giving partial compensation to their owners for this compulsory action. This Order is about to be renewed for all cattle suffering from tuberculosis of the udder or from tuberculous emaciation, one-fourth of the market value if the disease is advanced, or otherwise three-fourths, being given to the owner. In these circumstances it will be interesting to ascertain how many are certified as suffering from advanced disease. From the same date the use of any cow for producing milk which gives tuberculous milk will be prohibited, and owners and veterinary practitioners are required to notify tuberculosis in cattle so soon as recognised by them. The last paragraph of the circular letter announcing the matter briefly summarised above adds somewhat deprecatingly: "The new Order represents the most that is practicable at the present time in the direction of securing the eradication of bovine tuberculosis, and in contributing to the production at the source of a milk supply free from bovine tubercle bacilli."
THIS statement on the official attitude in Great Britain towards bovine tuberculosis is commendably frank, and adequately reveals the weakness of the situation and the action-or is it merely " gesture "? -directed towards remedy. Disease is allowed to continue to become obvious to the farmer, and so obvious that he can no longer conceal it, or until a veterinarian is called upon the scene, and then the local authority-hereafter three-fourths of the money probably will be paid out of Exchequer funds-will pay three-fourths or one-fourth of the value of the condemned beast. There are some hundreds of herds of cattle in Great Britain from which tuberculosis has been eliminated by well-known and practicable scientific methods. Is it not likely that the resumption of compensation to the owners of beasts with advanced tuberculosis will delay the multiplication of tuberculosis-free herds ? Moreover, is it not arguable that, in the interest of the many thousands of young children in Great Britain who annually are made victims of tuberculosis from drinking infected milk, it might be better to save the millions sterling which will be paid in compensation for disease which

NO. 2908 , VOL. I I 6$]$ 